INFLAMMATORY BOWEL DISEASE

\title{
Reversal of abnormal collagen production in Crohn's disease intestinal biopsies treated with regenerating agents
}

\author{
C Alexakis, J P Caruelle, A Sezeur, J Cosnes, J P Gendre, H Mosnier, L Beaugerie, D Gallot, \\ M Malafosse, D Barritault, P Kern
}

Gut 2004;53:85-90

See end of article for authors' affiliations

Correspondence to: Professor D Barritault CRRET-CNRS FRE 2412, Faculté des Sciences de Créteil, Université Paris 12, Avenue du Général de Gaulle, 94010 Créteil cedex, France; barritault@ univ-paris $12 . f_{r}$

Accepted for publication 5 August 2003
Background: Crohn's disease (CD) is characterised by inflammation, muscle layer overgrowth, and collagenous fibrosis of the intestinal tract, with no effective therapy against collagen accumulation.

Aims: We quantified production of collagen in resection specimens from normal and CD patients and investigated the effect of regenerating agents (RGTAs) on collagen production. RGTAs are chemically substituted dextrans engineered to mimic the growth factor protecting effects of heparan sulphates. RGTAs have been shown to enhance tissue repair in various in vivo models and to modulate in vitro collagen phenotype differentially according to their structure.

Patients: We studied intestinal biopsies from two groups of CD patients: treated with glucocorticoids (CDGC group: 10 patients) or not treated (CD group: seven patients), and from seven control patients.

Methods: After 24 hours of ex vivo incubation with $\left({ }^{3} \mathrm{H}\right)$ proline, collagen I, III, and V were extracted by pepsin and quantitatively separated by sodium dodecyl sulphate-polyacrylamide gel electrophoresis. Biosynthesis of each collagen type was quantified on radiolabelled isolated collagen.

Results: Total intestinal collagen production in CD patients compared with controls was increased up to 3.5-fold overall $(p<0.001)$. In particular, collagen III biosynthesis was enhanced by 6.2 -fold $(p<0.001)$ in CD patients. In the CD-GC group, collagen production abnormalities were less marked. RGTAs added to the incubation medium in the CD group decreased total collagen production by $50 \%$ and decreased collagen III synthesis by $76 \%$.

Conclusion: This finding offers a rationale for using RGTAs in the treatment of intestinal fibrosis in CD, thus opening up a potential new therapeutic field for this family of drugs.
$C^{2}$ ohn's disease $(\mathrm{CD})$ is a chronic progressive disease of the gastrointestinal tract characterised by transmural granulomatous inflammation and thickening of the bowel wall, with muscle layer overgrowth and collagenous fibrosis. Excess of fibrillar collagens occurs in all bowel wall layers. $^{12}$ Recent findings suggest that increased collagen production may be pivotal in the mechanism leading to intestinal fibrosis, stricture development, and intestinal obstruction. ${ }^{3}$ Yet no medications effective against intestinal collagen accumulation are available, and surgery remains the main treatment for fibrosis related morbidity in CD. ${ }^{1}$

Quantitative and qualitative variations in collagen phenotype have been documented in CD patients with conflicting results. ${ }^{5-8}$

The situation is further complicated in the intestine by the heterogeneity of the cell population capable of producing collagens. Mesenchymal intestinal cells producing collagens include fibroblasts, smooth muscle cells, and myofibroblasts. $^{39}$ Our first objective was to investigate collagen production in specimens of entire intestinal tissue fragments rather than in isolated cells. We quantitated the ex vivo production of collagens by intestinal tissue biopsies collected surgically from CD patients treated or not with glucocorticoids. Control biopsies were macroscopically normal intestinal tissue fragments from patients with distal intestinal cancer.

Evidence that collagen, and collagen III in particular, overproduction is related to fibrosis ${ }^{8}$ has prompted a search for components capable of selectively regulating the production of specific collagen types. ${ }^{10}$ We have demonstrated previously that low molecular weight heparin specifically decreased collagen III production. ${ }^{11}$ Recently, we developed a family of heparan sulphate mimetic polymers engineered to stimulate tissue repair and protection in vivo, which we called ReGeneraTing Agents or RGTAs. These polymers are obtained by chemical substitutions of dextran (see fig 1 for detailed structures). In several experimental models, they promote healing of various tissues, including muscle, ${ }^{12}$ bone, ${ }^{13}$ skin,${ }^{14}$ and intestine. ${ }^{15}$ They also induce extracellular matrix remodelling by decreasing collagen production, ${ }^{16}{ }^{17}$ and collagen III production in particular, relative to other collagen types. ${ }^{18}$ Because this effect on collagen synthesis may be associated with an antifibrotic activity, we studied the effects of RGTAs on collagen overproduction by intestinal tissue affected by CD

\section{MATERIALS AND METHODS}

\section{Source of tissue}

Intestinal tissue was obtained from three groups of patients who required surgical intestinal resection (medical details on patients and precise tissue specimen origins are indicated in table 1). For CD patients, behaviour status was indicated according to the Vienna classification. ${ }^{19}$ The CD group included patients with $\mathrm{CD}$ who were not receiving glucocorticoids (CD group); the CD-GC group comprised patients with $\mathrm{CD}$ who were receiving glucocorticoids at a mean dose of approximately $30 \mathrm{mg}$ prednisone/day. Tissue specimens from

Abbreviations: RGTA, regenerating agent; $C D, C$ rohn's disease; $C D$ GC, Crohn's disease treated with glucocorticoids; TGF- $\beta 1$, transforming growth factor $\beta 1$; FGF-2, fibroblast growth factor $2 ; M_{r}$, molecular weight; ds, degree of substitution; SDS-PAGE, sodium dodecyl sulphatepolyacrylamide gel electrophoresis 


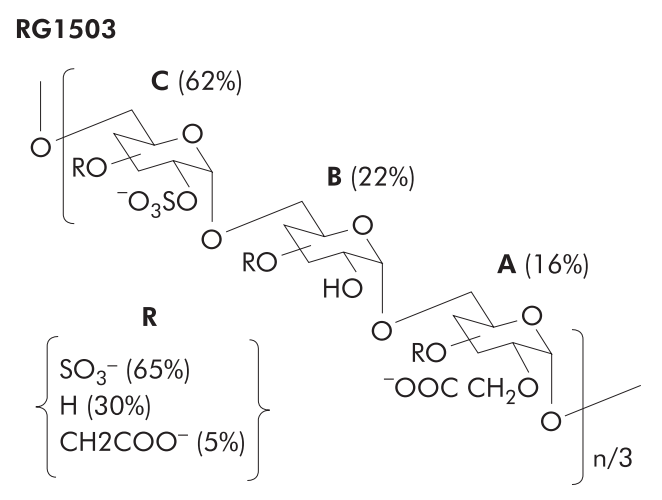

RG1192

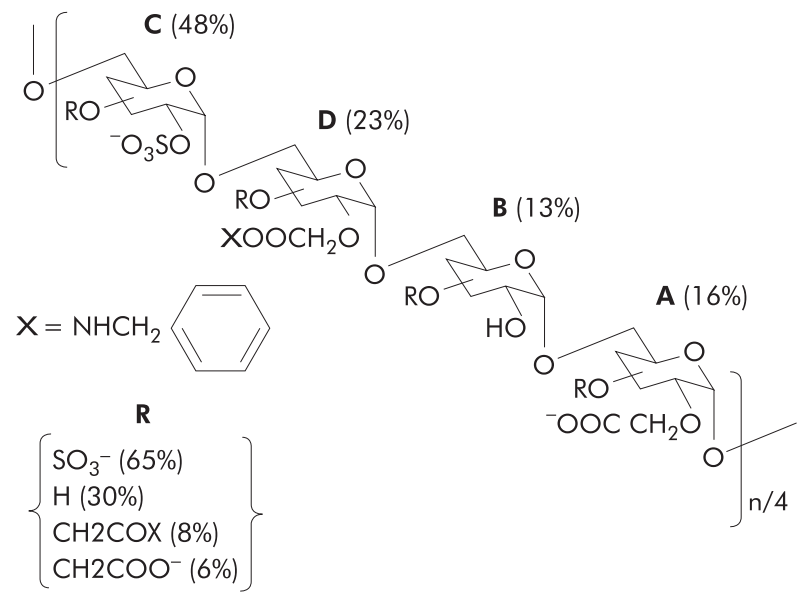

Figure 1 Schematic structure of dextran derivatives. Polymers were elaborated from T40 dextran by chemical substitutions, as described in materials and methods. Dextrans were substituted by carboxymethylation followed by O-sulphonation (RG1503) or by carboxymethylation followed by amidation with benzylamine and O-sulphonation (RG1192). The different percentages indicated were calculated from the degree of substitution (ds) relative to the position of each group in a glucosidic unit, as reported in table 2. For an easy representation, the substituted glucosidic units $A, B, C$, and D were arranged in an arbitrary combination. Their respective proportions (\%) within each polymer were calculated according to the nature of the group at the $C_{2}$ position. $R$ is the proportion (\%) of each substituted group at the $C_{3}$ plus $C_{4}$ positions.

patients in the CD and CD-GC groups were obtained from totally diseased areas with no portion of macroscopically normal tissue. In the control group, intestinal specimens were uninvolved areas of bowel removed from patients with distal intestinal cancer (at least $10 \mathrm{~cm}$ away from the tumour), with normal gross and histological features and no signs of inflammation.

\section{RGTA preparation}

The water soluble dextran derivatives RG1503 and RG1192 (see fig 1 for detailed structures) were prepared from T40 dextran (average molecular weight $\left(\mathrm{M}_{\mathrm{r}}\right) 37$ 000; Pharmacia, Paris, France) as previously described..$^{1820}$ Briefly, for RG1503, carboxymethyl dextran was synthesised from dextran T40 by carboxymethylation of $\mathrm{OH}$ residues with monochloracetic acid treatment. The presence of carboxymethyl groups was confirmed by infrared spectroscopy, which showed an absorption band at $1650 / \mathrm{cm}$. Then, RG1503 was obtained from carboxymethyl dextran by O-sulphonation. The presence of sulphate groups was indicated by infrared spectroscopy, with the appearance of two absorption bands at 1250 and $1025 / \mathrm{cm}$, respectively.

For RG1192, the carboxymethyl dextran was dissolved in $\mathrm{H}_{2} \mathrm{O} / \mathrm{EtOH}$, and carboxylate functions were activated with $\mathrm{N}$ ethoxy-carbonyl-2-ethoxy-1,2- dihydroquinoline for $30 \mathrm{~min}$ utes at $\mathrm{pH} 3.5$ and room temperature. This was followed by overnight incubation with 2 eq of free benzylamide. The product was precipitated and washed with methanol and dried under a vacuum. The infrared spectrum confirmed the presence of benzylamide with the appearance of a new absorption band at $1750 / \mathrm{cm}$, corresponding to the carbonyl bond of the amide. RG1192 was synthesised from the derivatised carboxymethyl-benzylamide dextran by O-sulphonation. The presence of sulphate groups was indicated by infrared spectroscopy, with the appearance of two absorption bands at 1250 and $1025 / \mathrm{cm}$, respectively.

Chemical characterisation of RG1503 and RG1192 was based on the degree of substitution (ds) of each individual group per glucosidic unit (table 2). A ds value of 3 indicates maximum substitution as one glucosidic unit contains three reactive $\mathrm{OH}$ groups at the $\mathrm{C}_{2}, \mathrm{C}_{3}$, and $\mathrm{C}_{4}$ positions. Each $\mathrm{ds}$ value was determined by acidimetric titration and elementary analysis and confirmed by ${ }^{1} \mathrm{H}$ nuclear magnetic resonance. The distribution of the three reactive $\mathrm{OH}$ groups is reported in table 2. Average molecular weights of the RGTA molecules were estimated by high performance size exclusion chromatography, as described previously..$^{20}$ These polymers did not show significant anticoagulant activity (less than $5 \mathrm{IU} / \mathrm{mg}$ compared with $173 \mathrm{IU} / \mathrm{mg}$ for heparin).

\section{Tissue processing}

Freshly resected tissue was placed in phosphate buffered saline and immediately transported to the laboratory for processing. In order to tentatively maintain uniformity in the sampling of tissue specimens, a standardised procedure was used to place each tissue specimen (approximately $1 \mathrm{~g}$ wet weight) on a cutting board and to slice it longitudinally into three pieces of similar macroscopic aspect and of approximately equal size.

\section{Intestinal collagen production}

One of the three parts of each specimen was incubated in $3 \mathrm{ml}$ of standard medium (Dulbecco's modified Eagle's minimal essential medium) supplemented with $100 \mathrm{IU} / \mathrm{ml}$ penicillin, $100 \mu \mathrm{g} / \mathrm{ml}$ streptomycin, and $2 \mathrm{mM}$ glutamine. The two other parts were incubated in $3 \mathrm{ml}$ of standard medium with RG1503 (100 $\mathrm{g} / \mathrm{ml})$ or RG1192 (100 $\mu \mathrm{g} / \mathrm{ml})$, respectively. Then, tissue specimens were labelled for 24 hours with $\left(5-{ }^{3} \mathrm{H}\right)$ proline $(25 \mu \mathrm{Ci} / \mathrm{ml}, 30 \mathrm{Ci} / \mathrm{ml}$; Amersham, France) plus ascorbic acid $(50 \mu \mathrm{g} / \mathrm{ml})$. At the end of the labelling period, the tissue was washed extensively with distilled water until no radioactivity was detected in the washing solutions.

\section{Collagen extraction, identification, and quantitation}

Each tissue specimen (approximately $300 \mathrm{mg}$ wet weight) was finely minced and homogenised. A small aliquot of homogenised tissue (10-15 mg) was hydrolysed in $6 \mathrm{M} \mathrm{HCl}$ at $105^{\circ} \mathrm{C}$ for 24 hours, for determination of total protein production, total collagen content, and total collagen production. Total protein production and total collagen production were determined by quantitation of $\left({ }^{3} \mathrm{H}\right)$ proline and hydroxy $\left({ }^{3} \mathrm{H}\right)$ proline by high performance liquid chromatography. ${ }^{22}{ }^{23}$ Total collagen content was determined by colorimetric hydroxyproline assay.

Then, all of the remaining minced tissue was digested with pepsin, as previously described. ${ }^{22}{ }^{24}$ Briefly, the tissue was dispersed in $0.5 \mathrm{M}$ acetic acid containing pepsin (with a collagen to pepsin ratio of $10: 1$ ) for 24 hours at $4^{\circ} \mathrm{C}$ under 
Table 1 Intestinal tissue specimens included in the study

\begin{tabular}{|c|c|c|c|c|c|}
\hline Age (y) & Sex & Diagnosis & $C D$ duration $(y)$ & Surgical procedure & $\mathrm{B} / \mathrm{T}$ \\
\hline \multicolumn{6}{|c|}{ Control group } \\
\hline 70 & $\mathrm{~F}$ & Right colon cancer & & Right hemicolectomy & $-/ C$ \\
\hline 62 & $M$ & Right colon adenocarcinoma & & Right hemicolectomy & $-/ C$ \\
\hline 55 & M & Small intestine carcinoma & & lleum resection & $-/ 1$ \\
\hline 77 & $\mathrm{~F}$ & Right colon cancer & & Right colectomy & $-/ C$ \\
\hline 79 & $M$ & Right colon adenocarcinoma & & Right hemicolectomy & $-/ C$ \\
\hline 78 & $\mathrm{~F}$ & Right colon cancer & & Right hemicolectomy & $-/ C$ \\
\hline 51 & M & Colorectal cancer & & Proctocolectomy & $-/ C$ \\
\hline \multicolumn{6}{|c|}{$C D$ group } \\
\hline 48 & $\mathrm{~F}$ & $C D$, fistulas & 3 & Ileocaecal resection & $\mathrm{B} 3 / \mathrm{O}$ \\
\hline 42 & $\mathrm{~F}$ & $C D$, bowel obstruction & 3 & lleocaecal resection & $\mathrm{B} 2 / \mathrm{O}$ \\
\hline 25 & $\mathrm{~F}$ & $C D$, bowel obstruction & 6 & Ileocaecal resection & $\mathrm{B} 2 / \mathrm{O}$ \\
\hline 24 & $\mathrm{~F}$ & $C D$, ileosigmoid fistula+bowel obstruction & 3 & Ileocaecal resection & $\mathrm{B} 3 / \mathrm{O}$ \\
\hline 21 & $M$ & $C D+$ bowel obstruction & 11 & Resection of middle portion of small intestine & $\mathrm{B} 2 / \mathrm{I}$ \\
\hline 26 & $M$ & CD+bowel obstruction & 5 & lleocecal resection & \\
\hline 21 & $\mathrm{~F}$ & CD+bowel obstruction & 6 & Resection of small intestine & $\mathrm{B} 2 / \mathrm{I}$ \\
\hline \multicolumn{6}{|c|}{ CD-GC group } \\
\hline 24 & $\mathrm{~F}$ & $C D$, ileosigmoid fistula & 3 & lleocaecal resection & $\mathrm{B} 3 / \mathrm{O}$ \\
\hline 29 & M & $\begin{array}{l}C D \text {, right and transverse colon+bowel } \\
\text { obstruction }\end{array}$ & 4 & lleocolonic resection & $\mathrm{B} 2 / \mathrm{C}$ \\
\hline 27 & M & $C D$, bowel obstruction & 15 & Right ileocolonic resection & $\mathrm{B} 2 / \mathrm{C}$ \\
\hline 38 & M & $C D$, bowel obstruction & $9 \mathrm{mo}$ & lleocecal resection & $\mathrm{B} 2 / \mathrm{O}$ \\
\hline 36 & $\mathrm{~F}$ & $C D$, right and left colon & 6 & Ileocolonic resection & $\mathrm{B} 1 / \mathrm{C}$ \\
\hline 24 & $\mathrm{~F}$ & $C D$, perineal lesions+bowel obstruction & 4 & lleocecal resection & $\mathrm{B} 2 / \mathrm{O}$ \\
\hline 28 & $\mathrm{~F}$ & $C D$, bowel obstruction & 6 & lleocecal resection & $\mathrm{B} 2 / \mathrm{O}$ \\
\hline 34 & M & $C D$, bowel obstruction & 2 & Ileal and ileocaecal resection & $\mathrm{B} 2 / \mathrm{I}$ \\
\hline 20 & M & $C D$, bowel obstruction & 3 & lleocaecal resection & $\mathrm{B} 2 / \mathrm{O}$ \\
\hline 30 & M & $C D$, bowel obstruction & 3 & Right colectomy & $\mathrm{B} 2 / \mathrm{C}$ \\
\hline \multicolumn{6}{|c|}{$\begin{array}{l}\text { The control group is defined in materials and methods; CD group, patients with Crohn's disease not treated with glucocorticoids; CD-GC group, patients with } \\
\text { Crohn's disease treated with glucocorticoids. } \\
\text { B, behaviour status (non-stricturing non-penetrating (B1), stricturing (B2), penetrating (B3)) according to the Vienna classification. }{ }^{19} \\
\mathrm{~T} \text {, tissue origin of the portion of specimen studied (I, ileal; O, ileocaecal; C, colonic). }\end{array}$} \\
\hline
\end{tabular}

constant shaking. This procedure was repeated twice. The insoluble material was hydrolysed in $6 \mathrm{M} \mathrm{HCl}$ at $105^{\circ} \mathrm{C}$ for 24 hours, for determination of residual insoluble collagen (hydroxyproline). In all specimens, the amount of insoluble collagen was less than $10-15 \%$ of the total intestinal collagen.

Production of pepsin soluble collagen types was determined by sodium dodecyl sulphate-polyacrylamide gel electrophoresis (SDS-PAGE). ${ }^{22}$ Collagen bands were revealed by Coomassie blue staining and identified by comparison with standard collagen types (I, III, and V). Separation of collagen III was achieved by delayed reduction. ${ }^{25}$ The relative proportions of radioactivity incorporated in collagens I, III, and V were quantified by excision of each individual collagen band followed by hydrolysis of the band in $6 \mathrm{M} \mathrm{HCl}$ at $105^{\circ} \mathrm{C}$ for 24 hours and by determination of hydroxy $\left({ }^{3} \mathrm{H}\right)$ proline in the hydrolysate. ${ }^{22}$

\section{Statistical analysis}

For all parameters reported in the text and tables, results are expressed as the mean (SD) of independent determinations carried out in triplicate on each tissue specimen with or without RGTA treatment. Differences between means in the two groups were evaluated using the Student's unpaired $t$ test. A p value $<0.05$ was considered statistically significant.

\section{RESULTS}

\section{Collagen content}

The collagen content of intestinal tissue from the CD, CD-GC, and control groups was determined by quantitation of hydroxyproline per unit of tissue wet weight. Total collagen content was significantly higher in the CD and CD-GC groups than in the control group (362 (44) $(\mathrm{p}<0.001)$ and $287(32)$ $(\mathrm{p}<0.02)$, respectively, versus 183 (20) $\mathrm{mg}$ collagen/10 g tissue wet weight). Brief exposure ( 24 hours) of intestinal tissue to the RGTAs had no significant effect on total collagen content in any of the three groups.

\section{Collagen production}

Each intestinal specimen was cut into three pieces: one was left untreated, one was treated with RG1503, and one was

Table 2 Chemical characterisation of the regenerating agents (RGTA)

\begin{tabular}{|c|c|c|c|c|c|c|c|c|c|}
\hline \multicolumn{4}{|l|}{$\mathrm{ds}^{*}$} & \multicolumn{6}{|c|}{ Position of groups expressed as ds } \\
\hline \multirow[b]{2}{*}{$\mathrm{CM}+$} & \multirow[b]{2}{*}{ Suł } & \multirow[b]{2}{*}{$\mathrm{CMB} \S$} & \multirow[b]{2}{*}{ Hबा } & \multicolumn{2}{|l|}{ CM } & \multicolumn{2}{|l|}{ Su } & \multicolumn{2}{|l|}{$\mathrm{CMB}$} \\
\hline & & & & $\mathrm{C}_{2}$ & $\mathrm{C}_{3}+\mathrm{C}_{4}{ }^{* *}$ & $\mathrm{C}_{2}$ & $\mathrm{C}_{3}+\mathrm{C}_{4}$ & $\mathrm{C}_{2}$ & $\mathrm{C}_{3}+\mathrm{C}_{4}$ \\
\hline \multicolumn{10}{|c|}{ Polymer RG1192 (average Mr 140 000) } \\
\hline $\begin{array}{l}0.31 \\
\text { Polym }\end{array}$ & $\begin{array}{r}1.38 \\
1503\end{array}$ & $\begin{array}{l}0.39 \\
\text { verage } 1\end{array}$ & $\begin{array}{c}0.92 \\
62900)\end{array}$ & 0.19 & 0.12 & 0.45 & & 0.23 & 0.16 \\
\hline 0.26 & 1.92 & & 0.82 & 0.16 & 0.10 & 0.62 & 1.30 & & \\
\hline
\end{tabular}

Chemical characterisation of each RGTA polymer is detailed in materials and methods.

*ds, degree of substitution of an individual group in one glucosidic unit (SD of ds values were less than $5 \%$, with $\mathrm{n}=3$ ).

$\dagger \mathrm{CM}, \mathrm{CH}_{2} \mathrm{COONa} ; \ddagger \mathrm{Su}, \mathrm{SO}_{3} \mathrm{Na} ; \S \mathrm{CMB}, \mathrm{CH}_{2} \mathrm{CONHCH}_{2} \mathrm{C}_{6} \mathrm{H}_{5} ;-\mathrm{H}$, non-reacted hydroxyl groups; ${ }^{* *} \mathrm{C}_{3}+\mathrm{C}_{4}$, global substitution at the $\mathrm{C}_{3}+\mathrm{C}_{4}$ positions calculated for each group as the difference between the total ds value and the ds value at the $C_{2}$ position. 
Table 3 Effect of regenerating agents RG1503 and RG1 192 on total collagen production in the bowel of patients with Crohn's disease (CD)

\begin{tabular}{|c|c|c|}
\hline & $\begin{array}{l}\text { Protein production } \\
\text { (total } \mathrm{dpm} / \mu \mathrm{g} \text { proline) }\end{array}$ & $\begin{array}{l}\text { Collagen production }\left(10^{2} \mathrm{dpm} \text { hydroxy }\right. \\
\left({ }^{3} \mathrm{H}\right) \text { pro/mg collagen) }\end{array}$ \\
\hline Control group & $12900(1900)$ & $1750(220)$ \\
\hline$C D$ group & $15800(2600)$ & $6200(890)^{\star * *}$ \\
\hline CD group+RG1503 & $13800(2200)$ & $3090(470)^{*} \dagger$ \\
\hline CD group+RG1 192 & $15900(2400)$ & $5020(780)^{* *}$ \\
\hline CD-GC group & $14200(2100)$ & $3700(560)^{\star *}$ \\
\hline CD-GC group+RG1503 & $14300(2300)$ & 2450 (380)‡ \\
\hline CD-GC group+RG1192 & $13700(2200)$ & $3050(420)^{*}$ \\
\hline \multicolumn{3}{|c|}{$\begin{array}{l}\text { Control, } C D \text {, and CD-GC groups as described in table } 1 \text {. } \\
\text { RGTA treatment of normal intestinal tissue (control group) did not significantly change total collagen production } \\
\text { (data not shown). } \\
{ }^{*} p<0.05,{ }^{* *} p<0.01,{ }^{* *} p<0.001 \text { compared with the control group. } \\
t p<0.05 \text { between RGTA treatment and no RGTA treatment of specimens from the CD group. } \\
\neq p<0.05 \text { between RGTA treatment and no RGTA treatment of specimens from the CD-GC group. }\end{array}$} \\
\hline
\end{tabular}

treated with RG1192. After 24 hours of labelling with $\left({ }^{3} \mathrm{H}\right)$ proline, total collagen production by the entire tissue fragment was determined (table 3). In the control group biopsies, RGTA treatment had no significant effect (data not shown). There were no significant differences in total protein production between the three groups. Total collagen production showed a marked increase in the CD group (by up to 3.5fold) and a smaller increase in the CD-GC group (by up to 2.1-fold). Treatment with RG1503 significantly decreased total collagen production in the CD and CD-GC groups, with a return to control values in the CD-GC group. RG1192 had no significant effect on total collagen production in the CD and CD-GC groups. Collagen in each tissue specimen was solubilised by pepsin treatment which produced similar yields in all three groups (the amount of residual insoluble collagen was less than $10-15 \%$ of total intestinal collagen). Fibrillar collagen types were separated and quantified by SDS-PAGE. Table 4 shows that production of collagen types I, III, and V exhibited large increases in the CD group and smaller increases in the CD-GC group. Treatment of CD biopsies with RG1503 decreased collagen III production to control values and also reduced production of collagens I and V. RG1192 decreased collagen III and collagen V production but had no effect on collagen I production. Treatment of CDGC biopsies with RG1503 restored collagen I and III production to control values but induced a smaller decrease in collagen V production; RG1192 reduced collagen III and collagen $\mathrm{V}$ production to control values but did not modify collagen I production.

We compared the relative percentages of production of each collagen type in each group (table 4). Without RGTA treatment, the proportion of collagen III in the CD group was selectively increased compared with the control group. Interestingly, both RG1503 and RG1192 specifically decreased the percentage of collagen III production to control values. Note that the relative proportion of collagen $\mathrm{V}$ production was higher with RG1503. In the CD-GC group, the proportion of collagen III production without RGTA treatment was not significantly increased compared with control values. However, both RG1503 and RG1192 selectively decreased the proportion of collagen III production in this group.

\begin{tabular}{|c|c|c|c|}
\hline & \multicolumn{3}{|c|}{$\begin{array}{l}\text { Collagen production }\left(10^{2} \mathrm{dpm} \text { hydroxy }\left({ }^{3} \mathrm{H}\right) \text { proline/mg collagen) }\right. \\
\text { (collagen type production as \% of total collagen production) }\end{array}$} \\
\hline & Collagen I & Collagen III & Collagen V \\
\hline $\begin{array}{l}\text { Control group } \\
\text { \% of total collagen } \\
C D \text { group } \\
\text { \% of total collagen } \\
C D \text { group+RG1503 } \\
\% \text { of total collagen } \\
C D \text { group+RG1192 } \\
\% \text { of total collagen } \\
C D-G C \text { group } \\
\% \text { of total collagen } \\
C D-G C \text { group+RG } 1503 \\
\% \text { of total collagen } \\
C D-G C \text { group+RG1192 } \\
\% \text { of total collagen }\end{array}$ & $\begin{array}{c}1300(180) \\
77.8(10.4) \\
3840(580)^{* * *} \\
63.6(9.6) \\
2260(360)^{*}+ \\
76.6(11.5) \\
3750(450)^{* * *} \\
79.9(13.2) \\
2430(370)^{*} \\
67.9(10.3) \\
1900(280) \\
82.9(12.5) \\
2330(350)^{*} \\
81.1(11.7)\end{array}$ & $\begin{array}{c}290(40) \\
17.4(2.4) \\
1800(280)^{* * *} \\
29.8(4.6)^{*} \\
430(70)+\dagger \dagger \\
14.6(1.9)^{\star \dagger} \\
690(100)^{* *}+\dagger \\
14.8(2.2)+\dagger \\
910(140)^{* *} \\
25.4(3.8) \\
230(40) \pm \pm \ddagger \\
10.9(1.7) \neq \ddagger \\
440(80) \pm \ddagger \\
3.4(0.5)\end{array}$ & $\begin{array}{c}80(10) \\
4.8(0.6) \\
390(60)^{* * *} \\
6.4(0.9) \\
260(50)^{* *} \dagger \\
8.8(1.5)^{*} \\
230(40)^{* *} \dagger \\
5.2(0.7) \\
240(40)^{* *} \\
6.8(1.0) \\
160(30)^{*} \\
6.9(1.1) \\
100(20) \neq \ddagger \\
15.5(3.0) \ddagger\end{array}$ \\
\hline \multicolumn{4}{|c|}{ 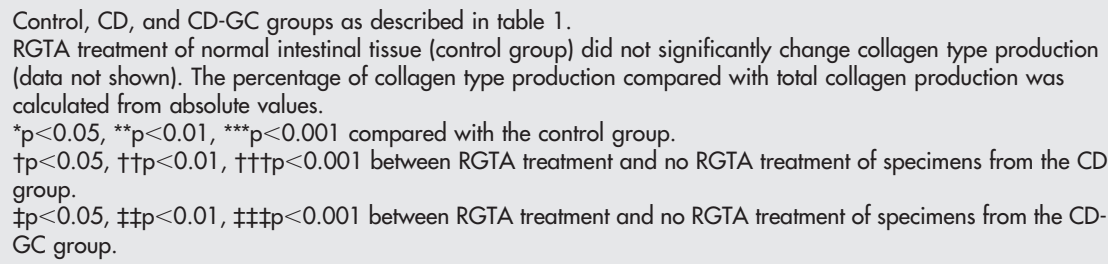 } \\
\hline
\end{tabular}




\section{DISCUSSION}

CD is a severe intestinal disorder characterised by a chronic and unpredictable course with flares of acute inflammation separated by remissions. ${ }^{26}$ The acute inflammation induces fibrosis with massive accumulation of a collagenous extracellular matrix. Onset of remission occurs when healing and repair mechanisms become operative. Thus antifibrotic drugs that enhance these mechanisms may hold therapeutic potential.

The goals of the present study were to improve the characterisation of collagenous fibrosis in human intestinal tissue from CD patients and to investigate the effect on this tissue of two antifibrotic compounds of the RGTA family, which promotes repair and remodelling of several tissues, ${ }^{12-14}$ including the intestine. ${ }^{15} 27$

Our results indicate that alterations in collagen production associated with CD were not related to an overall alteration in protein production, which was not significantly modified (table 3).

Intestinal collagen production was increased 3.5-fold in biopsies from CD patients who were not taking glucocorticoid therapy. Our study indicates an important increase in collagen III production, which reached 6.2-fold (table 4) versus 2.9 -fold and 4.8-fold for collagen I and collagen V, respectively. Increases in collagen III and also in collagen I production have been reported in fibrotic processes affecting various tissues, ${ }^{8}$ including the intestine. ${ }^{728}$

CD patients who were taking glucocorticoid therapy (CDGC group) had milder alterations in collagen production than patients in the $\mathrm{CD}$ group. The ability of glucocorticoids to decrease collagen production has been widely documented. ${ }^{29-31}$ However, in addition to exerting desirable effects on collagen production and inflammation, glucocorticoids inhibit wound healing and tissue repair.

In the present study, very brief ex vivo exposure (24 hours) to RGTA partially or completely corrected collagen production abnormalities in intestinal tissue from CD patients. In particular, RG1503 reduced the increase in collagen III production in the CD group from 6.2- to 1.5-fold of control levels. It should be noted that RG1503 had an overzealous inhibitory effect on the percentage of collagen III in the CDGC group, indicating that lower doses should be used in function of the present response of intestinal tissue.

In the CD-GC group, RGTA treatment almost completely restored the normal collagen expression phenotype group, suggesting that glucocorticoids and RGTA treatment may be complementary in the management of CD.

Differences were noted between the effects of RG1503 and RG1192. RG1503 was more effective in decreasing collagen I and III production and increased the percentage of collagen $\mathrm{V}$ in the CD group. RG1192 decreased the production of collagen III but not collagen I and had no effect on the percentage of collagen V. Differences in biological effects have been reported between RGTAs with or without benzylamide function substitution. ${ }^{18}{ }^{32}$ The activity of RG1503 is related mainly to interactions with transforming growth factor $\beta 1$ (TGF- $\beta 1$ ) whereas RG1192, which has a benzylamide function, could interact preferentially with fibroblast growth factor 2 (FGF-2)..$^{18} 3233$

Given that the increase in TGF- $\beta 1$ content in the CD intestine is among the key factors involved in the development of fibrosis, ${ }^{7}$ RG1503 might exert its activity on CD intestinal tissue by partly inhibiting or interfering with TGF$\beta 1$ activity.

RG1192 mainly affected the proportion of collagen III production. We have found considerably greater affinity of RG1192 for FGF-2 compared with RG1503, as well as abolition by FGF-2 neutralising antibody of the effect of RG1192 on collagen III production (unpublished data). Thus the effect of RG1192 on the CD collagen phenotype could be mediated by potentiation of the specific FGF-2 induced decrease in collagen III production. ${ }^{34}$

In addition, both RG1503 and RG1192 have been shown to inhibit the proliferation of various mesenchymal cells, ${ }^{17} 3235$ and thus RGTA may have beneficial effects on the abnormal cellular proliferation seen in CD.

Although the duration of tissue exposure to RGTA was extremely short in our study, the results suggest that these polymers may hold promise for correcting the collagen production abnormalities seen in $\mathrm{CD}$, thus providing a noninvasive alternative to surgery. Regular heparin and low molecular weight heparin have shown some efficacy in treating the bowel inflammation seen in CD. However, treatment duration was kept short because of the risk of bleeding and the rationale for using heparin is unclear. RGTAs are heparan sulphates mimetic agents devoid of anticoagulant activity. Thus our findings indicate that further clinical research is warranted.

\section{ACKNOWLEDGEMENTS}

This work was supported by the CNRS, the "Ministère de l'Enseignement Supérieur", and by the association Naturalia et Biologia. CA was a recipient of a grant from "Association François Aupetit".

\section{Authors' affiliations}

C Alexakis, J P Caruelle, D Barritault, P Kern, CRRET/CNRS FRE 2412, Université Paris-12, 94010 Créteil Cedex, France

A Sezeur, H Mosnier, Chirurgie Digestive et Colioscopique, Hôpital des Diaconesses, 75571 Paris Cedex 12, France

J Cosnes, J P Gendre, L Beaugerie, Gastroentérologie, Hôpital Rothschild, 75571 Paris Cedex 12, France

D Gallot, M Malafosse, Chirurgie Générale, Hôpital Bichat, 75018 Paris, France

\section{REFERENCES}

1 Becker JM. Surgical therapy for ulcerative colitis and Crohn's disease. Gastroenterol Clin North Am 1999;28:371-90.

2 Graham MF, Willey A, Adams J, et al. Corticosteroids increase procollagen gene expression, synthesis and secretion by human intestinal smooth muscle cells. Gastroenterology 1999;109:1454-61.

3 Pucilowska JB, Williams KL, Lund PK, et al. Fibrosis and inflammatory bowel disease: cellular mediators and animal models. Am J Physiol Gastrointest Liver Physiol 2000;279:G653-9.

4 Alexander-Williams J. Traumatic perforation of the bowel. Injury 2000;21:294-5.

5 Alexander AC, Irving MH. Accumulation and pepsin solubility of collagens in the bowel of patients with Crohn's disease. Dis Colon Rectum 1990;33:956-62.

6 Graham MF, Diegelmann RF, Elson CO, et al. Collagen content and types in the intestinal strictures of Crohn's disease. Gastroenterology 1988;94:257-65

7 Lawrance IC, Maxwell L, Doe W. Inflammation location but not type, determines the increase in TGF betal and IGFI expression and collagen deposition in IBD intestine. Inflamm Bowel Dis 2000;7:16-26.

8 Stallmach A, Schuppan D, Riese HH, et al. Increased collagen type III synthesis by fibroblasts isolated from strictures of patients with Crohn's disease. Gastroenterology 1992;102:1920-9.

9 Powell DW, Mifflin RC, Valentich JD, et al. Myofibroblasts. II. Intestinal subepithelial myofibroblasts. Am J Physiol Cell Physiol 1999;277:C183-201.

10 O'Kane S, Fergusson MWJ. Transforming growth factor betas and wound healing. Int J Biochem Cell Biol 1997;29:63-8.

11 Asselot-Chapel C, Combacau L, Labat-Robert J, et al. Expression of fibronectin and interstitial collagen genes in smooth muscle cells: modulation by low molecular weight heparin fragments and serum. Biochem Pharmacol 1995;49:653-9.

12 Aamiri A, Mobarek A, Carpentier G, et al. Effects of substituted dextran on reinnervation of a skeletal muscle in adult rats during regeneration. $C R$ Acad Sci III 1995;318:1037-43.

13 Lafont J, Baroukh B, Berdal A, et al. RGTA1 1, a new healing agent, triggers developmental events during healing of craniotomy defects in adult rats. Growth Factors 1998; 16:23-38.

14 Meddahi A, Blanquaert F, Saffar JL, et al. New approches to tissue regeneration and repair. Pathol Res Pract 1994;190:923-8.

15 Meddahi A, Benoit J, Ayoub N, et al. Heparin-like polymers derived from dextran enhance colonic anastomosis resistance to leakage. J Biomed Mater Res 1996;31:293-7. 
16 Logeart D, Letourneur D, Jozefonvicz J, et al. Collagen synthesis by vascular smooth muscle cells in the presence of antiproliferative polysaccharides. J Biomed Mater Res 1996;30:501-8.

17 Benazzoug Y, Logeart D, Labat-Robert J, et al. Derivatized dextrans modulate collagen synthesis in aortic smooth muscle cells. Biochem Pharmacol 1995:49:847-53.

18 Mestries $\mathbf{P}$, Borchiellini C, Barbaud C, et al. Chemically modified dextrans modulate expression of collagen phenotype by cultured smooth muscle cells in relation to the degree of carboxymethyl, benzylamide and sulfation substitutions. J Biomat Med Res 1998;42:286-94.

19 Gasche C, Scholmerich J, Brynskov J, et al. A simple classification of Crohn's disease: report of the Working Party for the World Congresses of Gastroenterology, Vienna 1998. Inflamm Bowel Dis 2000;6:8-15.

20 Chaubet F, Champion J, Maiga $O$, et al. Synthesis and structure-anticoagulant property relationships of functionalized dextran. Carbohydr Polym 1995;28: 145-52

21 Ledoux D, Papy-Garcia D, Escartin Q, et al. Human plasmin enzymatic activity is inhibited by chemically modified dextrans. J Biol Chem 2000;275:29383-90.

22 Kern P, Menasche M, Robert L. Relative rates of biosynthesis of collagen type I, type $V$ and type VI in calf cornea. Biochem J 1991;274:615-17.

23 El Nabout R, Martin M, Remy J, et al. Collagen synthesis and deposition in cultured fibroblasts from subcutaneous radiation-induced fibrosis. Modification as a function of cell aging. Matrix 1989:9:411-20.

24 Boyer B, Kern P, Fourtanier A, et al. Age dependent variations of the biosyntheses of fibronectin and fibrous collagens in mouse skin. Exp Gerontol 1988;26:375-83.

25 Sykes B, Puddle B, Francis $M$, et al. The estimation of two collagens from human dermes by interrupted gel electrophoresis. Biochem Biophys Res Com 1976;72:1472-80.
26 Meddahi A, Alexakis C, Papy-Garcia D, et al. Heparin-like polymer improved healing of gastric and colic ulceration. J Biomed Mater Res 2002;60:497-501.

27 Rubin E, Farber JL. Inflammatory bowel disease. In: Rubin E, Farber JL, eds. Pathology. Philadelphia: Lippincott JB, 1994:675-83.

28 von Lampe B, Barthel B, Coupland SE, et al. Differential expression of matrix metalloproteinases and their tissue inhibitors in colon mucosa of patients with inflammatory bowel disease. Gut 2000;47:63-73.

29 Shull S, Cutroneo KR. Glucocorticoids change the ratio of type III to type I procollagen extracellularly. Collagen Rel Res 1986;6:295-300.

30 Autio P, Oikarinen A, Melkko J, et al. Systemic glucocorticoids decrease the synthesis of type I and type III collagen in human skin in vivo, whereas isotretinoin treatment has no effect. Br J Dermatol 1994;131:660-3.

31 Anstead GM. Steroids, retinoids, and wound healing. Adv Wound Care 1998; 11:277-85.

32 Mestries $\mathbf{P}$, Alexakis C, Papy-Garcia D, et al. Specific RGTA increases collagen $V$ expression by cultured aortic smooth muscle cells via activation and protection of transforming growth factor-betal. Matrix Biol 2000;20:171-81.

33 Alexakis C, Guettoufi A, Mestries P, et al. Heparan mimetic regulates collagen expression and TGF-betal distribution in gamma-irradiated human intestinal smooth muscle cells. FASEB J 2001;15:1546-54.

34 Majors A, Ehrhart LA. Basic fibroblast growth factor in the extracellular matrix suppresses collagen synthesis and type III procollagen mRNA levels in arterial smooth muscle cells cultures. Arterioscler Thromb 1993; 13:680-6.

35 Senni K, Borchiellini C, Duchesnay A, et al. Antiproliferative polysaccharides modulate distribution and phenotypic expression of collagens by gingival fibroblasts. J Biomed Mater Res 1996;40:164-9.

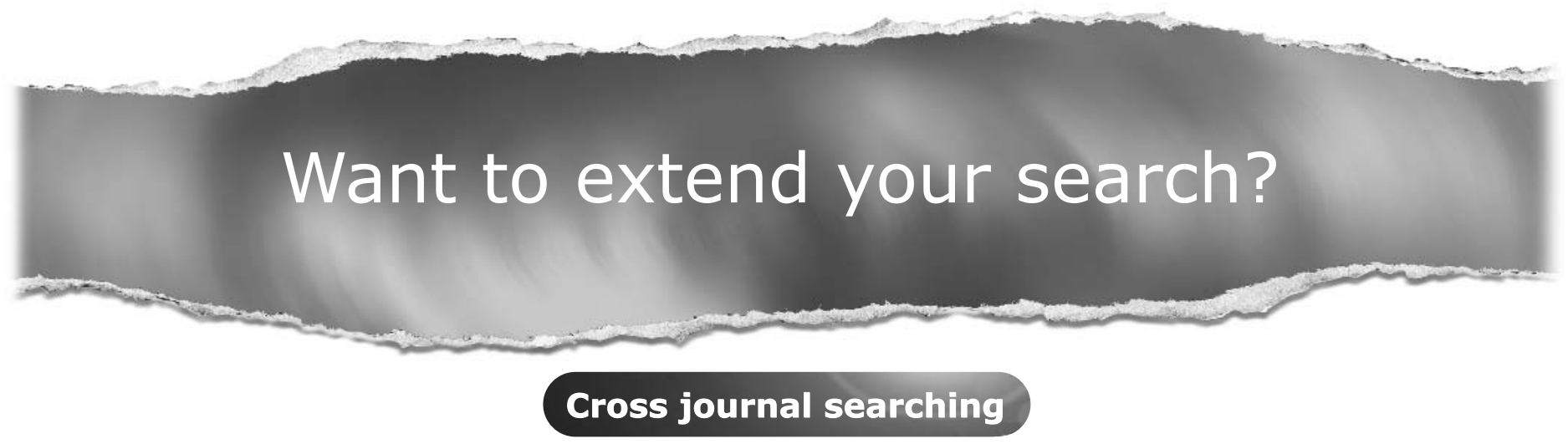

If you can't find what you are looking for in Gut you can extend your search across many of the more than 200 journals available for selection. You can restrict your search to specific subject areas (eg, clinical medicine, basic research), or select specific journals, or search all available titles.

\section{www.gutjnl.com}

